\title{
Modern Methods of Technological Mineralogy in Assessing the Quality of Rare Metal Raw Materials
}

\author{
E. Ozhogina ${ }^{(凶)}$, A. Rogozhin, O. Yakushina, Yu. Astakhova, \\ E. Likhnikevich, N. Sycheva, A. Iospa, and V. Zhukova \\ FSBE “All-Russian Institute of Mineral Raw Materials” (VIMS), \\ Moscow, Russia \\ vims@df.ru
}

\begin{abstract}
Modern technologies of mineralogical study and evaluation of rare metal raw quality are focused on its variety. Methods of the mineral processing, allowing to optimize monitoring of ore properties defining technological processes and quality of expected products are presented. Some examples of rare metal ores mineralogical study are given. The main challenging tasks in rare metal ores quality evaluation are considered.
\end{abstract}

Keywords: Technological mineralogy $\cdot$ Methods of analysis $\cdot$ Testing · Rare metals $\cdot$ Minerals $\cdot$ Ores $\cdot$ Specific features $\cdot$ Quality assurance $\cdot$ Quality assessment

\section{Introduction}

Variety of rare metal raw materials is determined, firstly, by a significant amount of industrial minerals, among which there are more than 20 main and about 30 minor and accessory minerals of different genesis; secondly, by the diversity of their genesis: magmatic, pegmatite, greisen, scarn, metamorphic, hydrothermal, sedimentary, hypergeneous. The rare metal-bearing minerals are the ones that contain Tantalum, Niobium, Bismuth, Tellurium, Zirconium, Hafnium, Yttrium, Scandium, Lanthanides, Lithium, Beryllium, Cesium, Rubidium, Strontium, Barium. A lot of rare metal ores, mainly tantalum-niobium, rare-earth phosphate, carbonate and silicate, and frequently zirconium, are radioactive. The vast majority of rare-metal ores are complex, and industrial minerals can be both main, and secondary, subordinate ones. General features of the rare metal-bearing ores are as follows:

- complex texture-structural pattern (a significant number of fine, metacolloidal spots formed by minerals and aggregates of micro-and nanometer size);

- polymineral composition associated with the simultaneous presence of minerals developed in different paragenetic associations;

- variations in chemical composition of the ore-forming minerals caused by chemical elements isomorphic substitutions in their crystal structure; 
- mineral grains phase heterogeneity of various origin, namely decay of solid solutions, syngeneic inclusions, zonal growth, multiple stages of generation, partial recrystallization, secondary solid-phase transformations, etc.;

- ore minerals with radioactive elements can undergo transformations resulting in metamictic forms origin (disrupted crystal structure due to radiation damage) or partially metamictic (damaged crystal structure due to radiation).

\section{Methods and Approaches}

The variety and complexity of rare metal ores mineralogical features identify the necessity to use a set of modern physical research methods of analysis to get reliable data on their composition and structure. This complex of mineralogical methods is individually selected depending on ores features and research tasks.

Mineralogical study of rare metal ores is necessary at all stages of deposits exploration and development. We particularly note the importance of ore mineralogical and analytical study of at the early stages of geological exploration, that allow to carry out technological assessment of raw materials with minimal investment, and at deposit exploration, involving geological and technological mapping for the detailed study of the mineralization zoning, minerals and mineral associations distribution, variations in the orebearing phases properties and characteristics, identification of the technological types and species whiting the geological margins of the deposit. The research practice proves great contribution of mineralogical study in deposits investigation and quality assessment.

When mineralogical investigation is the result of a set of implemented methods, including not only usually traditional ones (optical microscopy, radiography), but also precise analysis (analytical electron microscopy, microprobe). Mineral and technological mapping challenge today the Zashikhinsky, Tomtor, Chuktukon and other deposits of rare earth elements.

\section{Results and Discussion}

The characteristic feature of technological mineralogy is integration/conjunction of research methods and modern technical means/units. It is especially important when studding the rare-metal mineralization, because it is not always possible to uniquely identify industrially valuable minerals, to establish the mineral form of useful components, to identify and study characteristics of minerals appearing in the fine aggregates.

Pyrochlore-Mmonazite-Crandallite ores of the Tomtor deposit differ in specific composition, are rich in content and reserves of REE, Niobium, Yttrium, Scandi- um, Phosphorus and are a non-standard type of rare-metal raw materials. Ores features are the variable granular composition, often high dispersion, polymineral composition, various forms of occurrence the rare earths and niobium-bearing minerals, the character of their localization in close association with Alumiium- Silicate minerals. The ores are formed by polymineral aggregates with variable content of Crandallite and Kaolinite of fine-grained structure. The aggregate cement contains also Siderite, Ilmenorutil, 
Anatase, Pyrochlore, iron hydroxides, and other minerals. Most often the aggregates dispose earthy-type structure.

Pyrochlore is the main Niobium mineral, that form both individual octahedral crystals, fragments of rounded and angular forms, as well as aggregates of tiny grains in size ranging from $1 \mu \mathrm{m}$ to $0.5 \mathrm{~mm}$, in varying degrees transformed by hypergene processes. The rock is distributed in the form of microinclusions, forming a "rash" in the cementing mass of aluminophosphates and silicates. According to microprobe data (X-ray microspectral microanalysis), the main feature of the hypergenic alteration of Pyrochlore is the replacement of $\mathrm{Ca}$ and $\mathrm{Na}$ by $\mathrm{Sr}, \mathrm{Ba}$ and $\mathrm{Pb}$; the altered Pyrochlore varieties significantly dominate in the ores. Hypergeneous transformation of Pyrochlore was accompanied by textural transformations, typically clearly manifested in the disintegration of its large crystals into small blocks (Fig. 1). Often the cracks between the separate Pyrochlore individuals are filled by Crandallite group minerals and Apatite, rarely by sulfides.
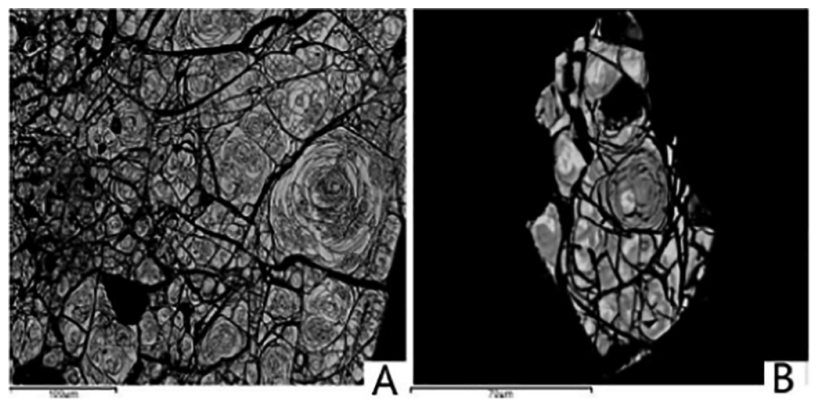

Fig. 1. Disintegrated crystals of Pyrochlore. TEM, image in back scattered electrons

Minerals of Crandallite group mostly form polymineral aggregates being dominant phase in these aggregates. There is a weak individualization of isometric and round shape grains, closely associated with fine Pyrochlore, Monazite, iron hydroxides, their grain size in the ores is often much less than 5 micrometers. According to microprobe analysis, the Crandallite group minerals have a mixed composition. According to X-ray powder diffraction analysis (XPD), the interplanar distances $d(h k l)$ reliably identificate Gorceixite $(2.96,3.55,5.72 \AA)$ and the intermediate Goyazite-Florencite series (2, 94, 3, 53, of $5.71 \AA)$.

Mineralogical features of a Pyrochlore-Monazite-Crandallite ores (variable granular composition, often with high dispersion; polymineral composition due to the simultaneous presence of different paragenesis assemblages, different form of Niobium and rare earths presence, vide range of isomorphic substitutions in the structure of minerals, the proximity of their physical properties) determine the impossibility of these ores processing by methods of deep enrichment. Therefore, the prospects of such ores processing should be associated with hydrometallurgy.

Typical features of the Chuktucon Deposit rare earth ores were established on electron microscopic study. The main ore minerals are Pyrochlore, Monazite and the 
Crandallite group minerals. All of them are superfinely dispersed and are in close assemblage/association with Iron and Manganese oxides and hydroxides. The latter form complex types of accretions with Pyrochlore (corrosive), Monazite (envelope of Goethite around Monazite grains), Crandallite group minerals (thin jointing), which negatively affects their disclosure and does not allow to identify and study these minerals by traditional methods of optic microscopy. Microprobe study indicated varieties of secondary Pyrochlore (bearing Cerium, Barium, Strontium and mixed type), and variable chemical composition of the Crandallite group minerals. Almost constant presence of Iron and Manganese mechanical impurities was established in all ore minerals. An independent mineral form of Cerium - Cerianite has been identificate by X-ray powder diffraction data.

\section{Conclusions}

The main challenging tasks for the rare metal ores investigation and quality evaluation should be considered:

- predictive mineral and technological assessment of raw materials of natural and man-made origin;

- geological and technological mapping using an Arsenal of methods of technological Mineralogy;

- forecasting of technological properties of ores at various stages of processing and development of methods of their directed change;

- increase of complexity of development of deposits and deep processing of ores;

- identification and involvement in the industrial use of non-traditional types of rare metal raw materials;

- assessment of environmental consequences of industrial development of deposits.

Therefore, the main task of technological mineralogy in the study of the rare metal ores is today their comprehensive study for quality assessment at all stages of geological research and development of mineral deposits.

Open Access This chapter is licensed under the terms of the Creative Commons Attribution 4.0 International License (http://creativecommons.org/licenses/by/4.0/), which permits use, sharing, adaptation, distribution and reproduction in any medium or format, as long as you give appropriate credit to the original author(s) and the source, provide a link to the Creative Commons license and indicate if changes were made.

The images or other third party material in this chapter are included in the chapter's Creative Commons license, unless indicated otherwise in a credit line to the material. If material is not included in the chapter's Creative Commons license and your intended use is not permitted by statutory regulation or exceeds the permitted use, you will need to obtain permission directly from the copyright holder.

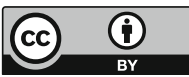

